\title{
Plastic flow potential for the cone region of the MRS-Lade model
}

\author{
by A. Pérez-Foguet ${ }^{1}$ and A. Huerta ${ }^{2 \dagger}$, Member, ASCE
}

1 Research Assistant, Departamento de Matemática Aplicada III, E.T.S. de Ingenieros de Caminos, Universitat Politècnica de Catalunya, Campus Nord C-2, E-08034 Barcelona, Spain.

2 Professor, Departamento de Matemática Aplicada III, E.T.S. de Ingenieros de Caminos, Universitat Politècnica de Catalunya, Campus Nord C-2, E-08034 Barcelona, Spain.

$†$ Corresponding author, e-mail: huerta@etseccpb.upc.es 


\begin{abstract}
The original formulation of the MRS-Lade model, with non-associated flow rule on the meridian plane in the cone region, has a corner. In order to reduce the computational effort of corner solution algorithms, a modified plastic flow potential for the cone part is found in the literature. This modification may have a non-admissible flip over of the flow vector in the cone-cap intersection if the plastic flow potential is not correctly defined. Here a corrected plastic flow potential for the cone region is defined to obtain a continuous transition of the flow vector.
\end{abstract}

Key words: computational plasticity, flow rule, cap-model, non-associated plasticity, dilatancy, corner problem.

\title{
INTRODUCTION
}

In computational plasticity, the definition of the plastic flow vector is more useful than the definition of the plastic flow potential. The flow vector is needed for the integration of the constitutive law and for the resolution of the global finite element problem, see Ortiz and Popov (1985), Simo and Taylor (1985), Runesson et al. (1988) and Crisfield $(1991,1997)$ among others. In fact, the flow potential is hardly ever employed, it is defined mainly for convenience (Lubliner, 1990). Nevertheless the flow potential is useful in theoretical analysis (Kim and Lade, 1988; Lubliner, 1990; Lade, 1994) and in the formal description of the

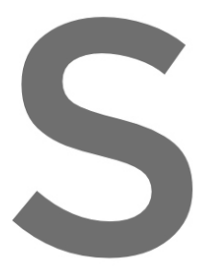

model, for in
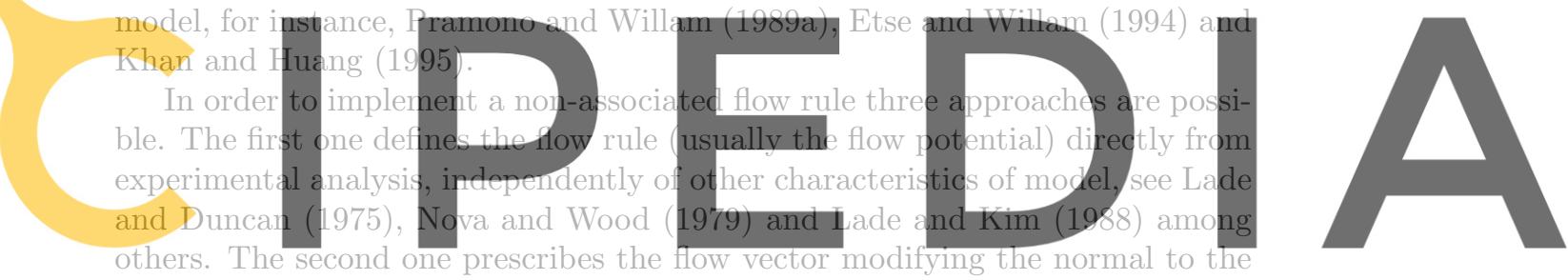

vield function (the corresponding flow potential is obtained by integration). see

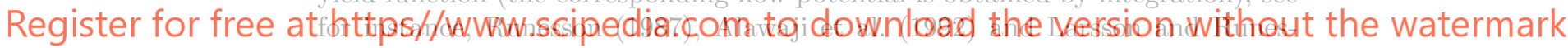

son (1996). The third one defines the flow potential as a direct modification of the vield function. Macari-Pasqualino et al. (1994), Jeremić and Sture (1994).

Macari et al. (1997); this must be done carefully in order to get the desired properties in the flow vector.

\section{MRS-LADE MODEL}

This work focuses in the non-associated flow rule for the cone region of the MRS-Lade model. This model has been developed at the University of Colorado by Macari-Pasqualino, Runesson and Sture (Sture et al., 1989; Jeremić and Sture, 1994; Macari et al., 1997) and it is a further development of Lade's threeinvariant model for cohesionless soils (Lade and Duncan, 1975; Lade, 1989).

The model has been used to simulate the behavior of granular materials, such as sand, under both low and high confinement stresses (Macari-Pasqualino et al., 1994; Macari et al., 1997). Quoting Jeremić and Sture (1997), the MRSLade model features: 
- a two-surface formulation, comprising a smooth cone surface and a smooth cap surface intersecting in plane curve (ellipse segment) in the deviatoric plane,

- hardening and softening variables for both surfaces are based on dissipated plastic work,

- a non-associated flow rule in the meridian plane and an associated flow rule in the deviatoric plane of the cone region, and an associated flow rule in the cap region,

- ability to model cohesive strength and a curved meridian in the cone region.

In order to center in the essential issue of this work, a simplified version of the original model is described here. Detailed discussion is presented by Sture et al. (1989) and Jeremić and Sture (1994).

The following expressions define the vield function

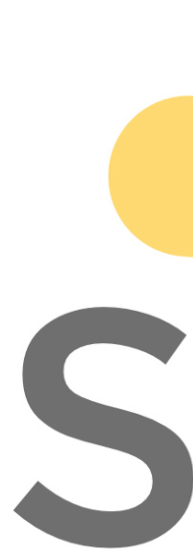

$$
\begin{aligned}
& F_{\text {cone }}=q g(\theta)-\eta_{\text {cone }} p=0 \\
& F_{\text {cap }}=\left(\frac{p-\alpha p_{\text {cap }}}{(1-\alpha) p_{\text {cap }}}\right)^{2}+\left(\frac{q g(\theta)}{\eta_{\text {cone }} \alpha p_{\text {cap }}}\right)^{2}-1=0
\end{aligned}
$$

where $p, q$ and $\theta$ are functions of the stress invariants, $g(\theta)$ is a function that defines the shape in the deviatoric plane, $\eta_{\text {cone }}$ and $p_{\text {cap }}$ are the hardening/softening functions, and $\alpha$ is a parameter of the model. A scheme of the trace of the yicld function in the $p-q$ plane is depicted in Fig. 1.

The flow rule is asspciated on the plane of the $F_{\text {cap }}$, and, does. Follo non-associated no

the cone region is represented by a plastic potential function of the form

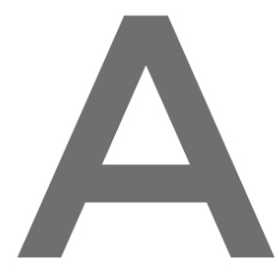

where $n$ is a non-negative constant. Typical values for $n$ are close to 0.1 . This potential reduces the dilatancy of the associated flow rule in the cone region. Note that for $n$ equal to zero incompressibility is enforced for values of $p$ between zero and $\alpha p_{\text {cap }}$. The components of the flow vector on the meridian plane, $\mathbf{m}=\left(m_{p}, m_{q}\right)$, are

$$
m_{p}=-n \eta_{\text {cone }} \quad m_{q}=g(\theta) .
$$

\section{MODIFIED PLASTIC FLOW POTENTIAL}

For the usual case, $n$ different than zero, this flow rule has a grey region at the intersection of cone and cap surfaces (see Fig. 1a). In this region there is not continuity of the flow vector. This implies that the Koiter's rule must be applied: the direction of the plastic strain rate is defined as a linear combination of the 
cone and cap flow vectors. Therefore, a corner solution algorithm is needed (Simo et al., 1988; Pramono and Willam, 1989b; Hofstetter et al., 1993; Jeremić and Sture, 1994). Such algorithms are usually expensive from a computational point of view. Thus, in order to reduce the computational effort, an alternative definition of the flow potential for the MRS-Lade model is presented in MacariPasqualino et al. (1994) and Macari et al. (1997). To avoid the grey zone, the flow vectors corresponding to cone and cap regions at the corner, i.e. $p=\alpha p_{\text {cap }}$, must have the same direction (see Fig. 1c). Thus the $p$-component of the cone flow vector must be zero at the corner.

The previously cited references propose the use of a pressure dependent $n$,

$$
n=-\gamma \frac{p-\alpha p_{\text {cap }}}{p+\alpha p_{\text {cap }}}
$$

where $\gamma$ is a non-negative constant. If Eq. (4) is used in (3) and the expression of the flow potential is not necessary at all, the grey zone disappears and a continuous variation of the flow vector is obtained. However, if Eq. (4) is directly substituted in (2), as Macari-Pasqualino et al. (1994), and Macari et al. (1997) seem to indicate, a modified flow potential is defined which induces the following components of the flow vector on the meridian plane,
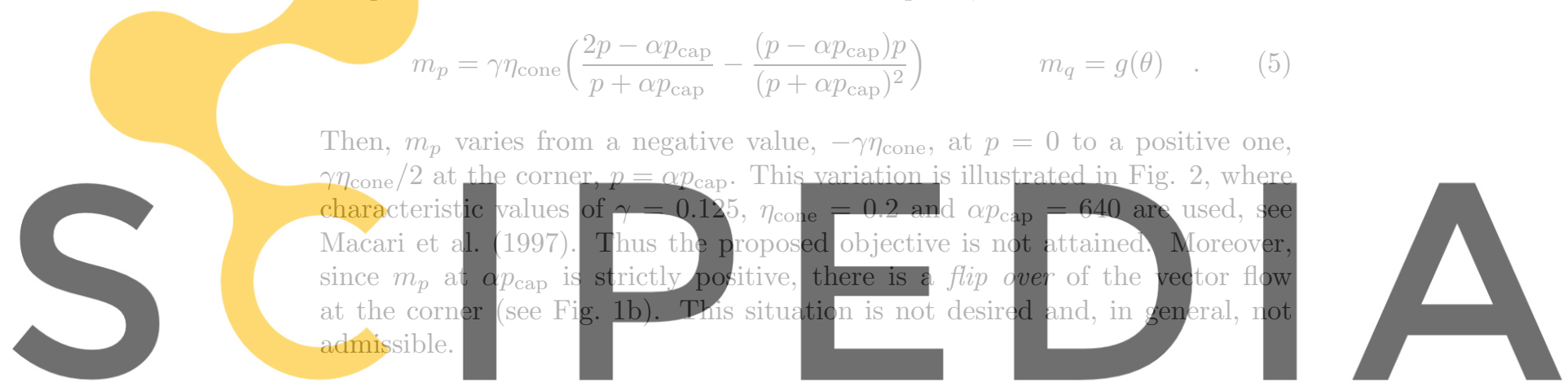

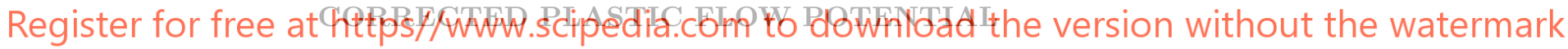

In order to obtain the desired flow vector a different flow potential must be defined. With the desired expression of the flow vector a flow potential is obtained by integration. After substitution of Eq. (4) into (3) the components of the flow vector, $\mathbf{m}^{\star}=\left(m_{p}^{\star}, m_{q}^{\star}\right)$, become

$$
m_{p}^{\star}=\gamma \eta_{\text {cone }} \frac{p-\alpha p_{\text {cap }}}{p+\alpha p_{\text {cap }}} \quad m_{q}^{\star}=m_{q}=g(\theta)
$$

As stated previously this flow vector induces the desired behavior. In Fig. 3, the variation of $m_{p}^{\star}$ with respect to $p$ is presented. In this case, the component $m_{p}^{\star}$ remains negative for every $p$ less then $\alpha p_{\text {cap }}$ and reaches zero at this limit. Therefore, the grey region disappears, without any flip over of the flow vectors, and a specially designed corner algorithm is precluded. Note that other expressions for the evolution of $m_{p}^{\star}$ reaching zero from below at $p=\alpha p_{\text {cap }}$ can be used, if they do conform with experimental results. 
The plastic flow potential corresponding to the flow vector defined in (6) is obtained by integration:

$$
G_{\text {cone }}^{\star}=q g(\theta)+\gamma \eta_{\text {cone }}\left(p-2 \alpha p_{\text {cap }} \ln \left(p+\alpha p_{\text {cap }}\right)\right),
$$

where the integration constants are taken equal to zero since the purpose of (7) is simply the definition of a potential for the plastic strain rate.

Eq. (7) represents a new plastic flow potential for the cone region of the MRS-Lade model. The corresponding flow vector components are defined in Eq. (6). This flow vector is justified from a physical view point in MacariPasqualino et al. (1994). But, the flow potential presented here will not induce the undesired features of the one presented in Macari-Pasqualino et al. (1994).

\section{CONCLUSIONS}

Flow potentials are seldom employed in computational plasticity if the flow vector is known a priori. Nevertheless, if they are needed for theoretical or verification purposes they must agree with the desired behavior of the flow vectors. If the flow rule is modified by acting on the flow vector, the corresponding flow potential should be obtained by simple integration. Here, a new plastic flow potential for the cone region of the MRS-Lade model is presented. This potential induces a flow vector with continuous transition between cone and cap regions. Thus, the corner problem (grey region) inherent to the original formulation and the non-admissible flip over of previously published modifications, are avoided.
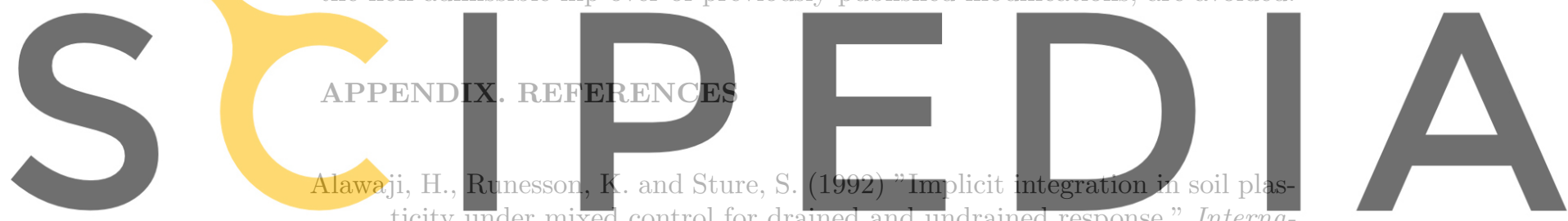

tional Journal for Numerical and Analytical Methods in Geomechanics,

Register for free at https//WWWA6scipedia.com to download the version without the watermark

Crisfield, M. A. (1991). Non-linear finite element analysis of solids and struc-

tures. Vol 1: Essentials, John Wiley \& Sons Ltd.

Crisfield, M. A. (1997). Non-linear finite element analysis of solids and structures. Vol 2: Advanced topics, John Wiley \& Sons Ltd.

Etse, G. and Willam, K. (1994). "Fracture energy formulation for inelastic behavior of plain concrete." Journal of Engineering Mechanics, 120(9), 1983-2011.

Hofstetter, G., Simo, J. C. and Taylor, R. L. (1993). "A modified cap model: closest point solution algorithms." Computers and Structures, 46(2), 203214.

Jeremić, B. and Sture, S. (1994). "Implicit integrations rules in plasticity: Theory and implementation." Technical Report to NASA Marshall Space Flight Center. Contract: NAS8-38779, University of Colorado at Boulder. 
Jeremić, B. and Sture, S. (1997). "Implicit integrations in elastoplastic geotechnics." Mechanics of Cohesive-Frictional Materials, 2, 165-183.

Kim, M. K. and Lade, P. V. (1988). "Single hardening constitutive model for frictional materials. I. Plastic potential function." Computers and Geotechnics, 5, 307-324.

Khan, A. S. and Huang, S. (1995). "Continuum theory of plasticity." John Wiley \& Sons Ltd., New York.

Lade, P. V. (1989). "Experimental observations of stability, and shear planes in granular materials." Ingenieur Arquiv, 59, 114-123.

Lade, P. V. (1994). "Instability and liquefaction of granular materials." Computers and Geotechnics, 16, 123-151.

Lade, P. V. and Duncam, J. M. (1975). "Elastoplastic stress-strain theory for cohesionless soil." Journal of Geotechnical Engineering, 101(10), 10371053.

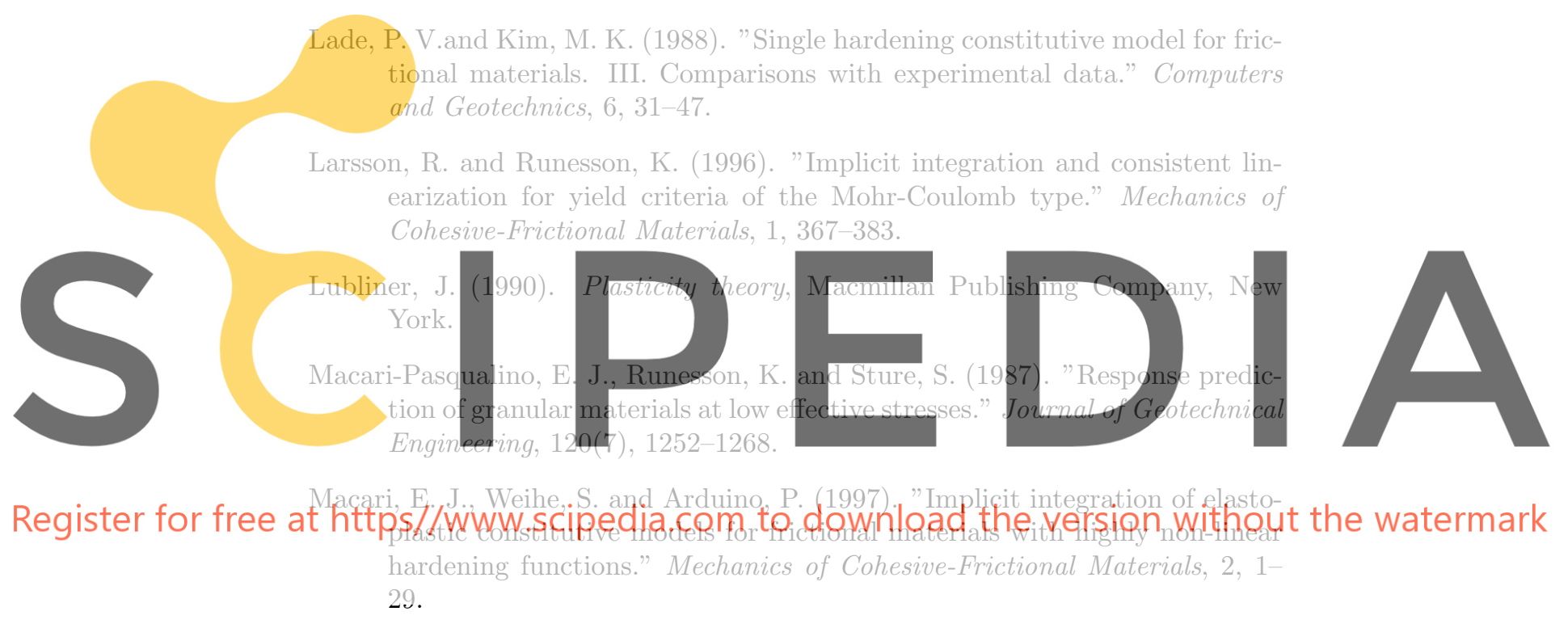

Nova, R. and Wood, D. M. (1979). "A constitutive model for sand in triaxial compression." International Journal for Numerical and Analytical Methods in Geomechanics, 3, 255-278.

Ortiz, M. and Popov, E. P. (1985). "Accuracy and stability of integration algorithms for elastoplastic constitutive relations." International Journal for Numerical Methods in Engineering, 21, 1561-1576.

Pramono, E. and Willam, K. (1989a). "Fracture energy-based plasticity formulation of plain concrete." Journal of Engineering Mechanics, 115(6), $1183-1204$.

Pramono, E. and Willam, K. (1989b). "Implicit integration of composite yield surfaces with corners." Engineering Computations, 6, 186-197. 
Runesson, K. (1987). "Implicit integration fo elastoplastic relations with reference to soils." International Journal for Numerical and Analytical Methods in Geomechanics, 11, 315-321.

Runesson, K., Sture, S. and Willam, K. (1988). "Integration in computational plasticity." Computers and Structures, 30(1/2), 119-130.

Simo, J. C., Kennedy, J. G., and Govindjee, S. (1988). "Non-smooth multisurface plasticity and viscoplasticity. Loading/unloading conditions and numerical algorithms." International Journal for Numerical Methods in Engineering, 26, 2161-2185.

Simo, J. C. and Taylor, R. L. (1985). "Consistent tangent operators for rateindependent elastoplasticity." Computer Methods in Applied Mechanics and Engineering, 48, 101-118.

Sture, S., Runesson, K. and Macari-Pasqualino, E. J. (1989). "Analysis and calibration of a three-invariant plasticity model for granular materials." Ingenieur Arquiv, 59, 253-266.
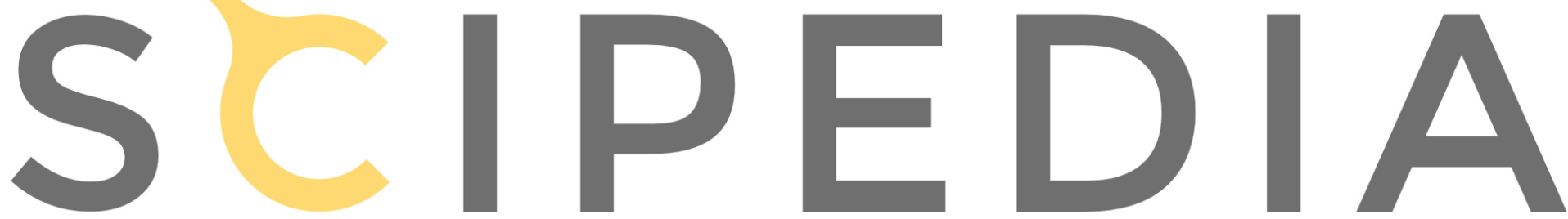

Register for free at https//www.scipedia.com to download the version without the watermark 


\section{FIGURE CAPTIONS}

Fig. 1 Trace of the simplified MRS-Lade yield function and characteristic flow vectors on the $p-q$ plane. Original formulation (a), modified flow potential (b) and corrected flow potential (c).

Fig. $2 p$-component of modified flow vector as function of $p$.

Fig. $3 p$-component of corrected flow vector as function of $p$.
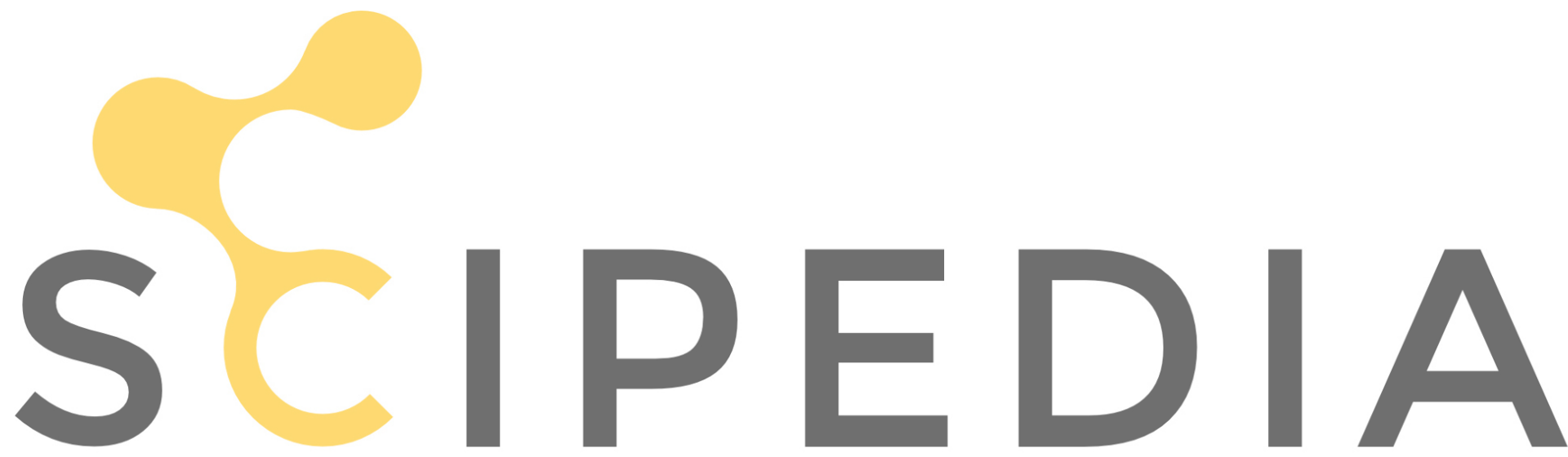

Register for free at https//www.scipedia.com to download the version without the watermark 


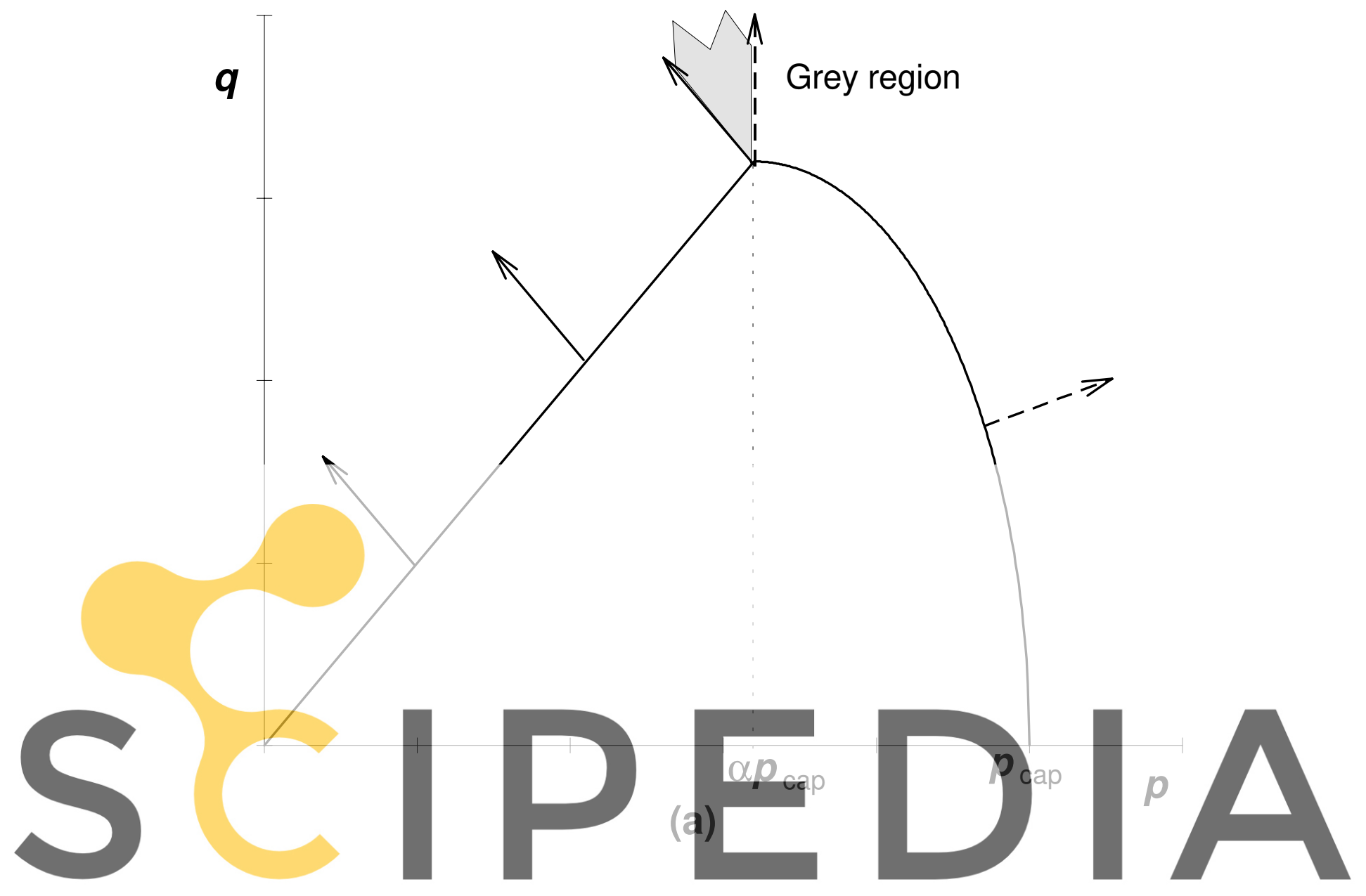

Register for free at https//www.scipedia.com to download the version without the watermark 


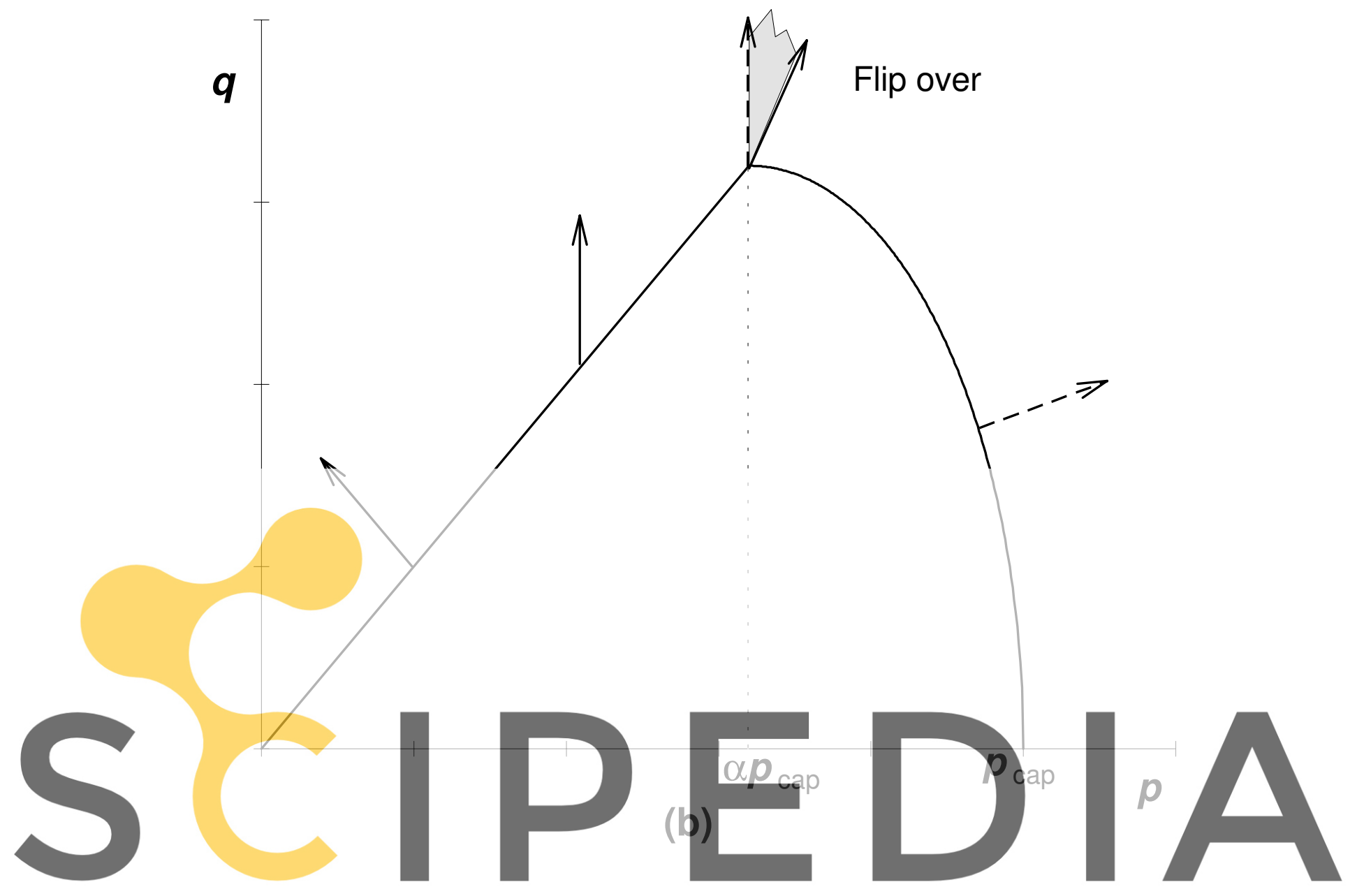

Register for free at https//www.scipedia.comito download the version without the watermark 


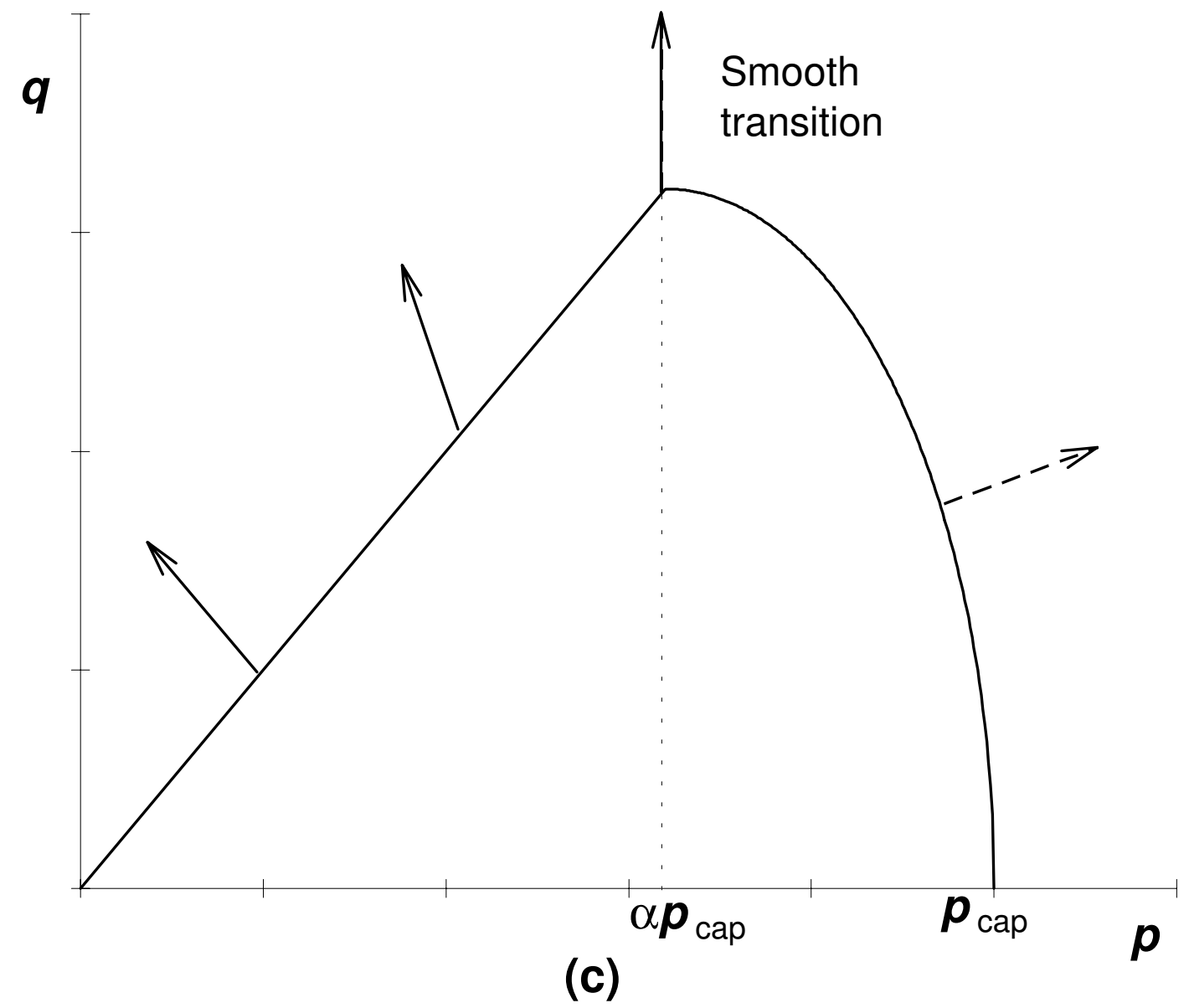

Figure 1c 


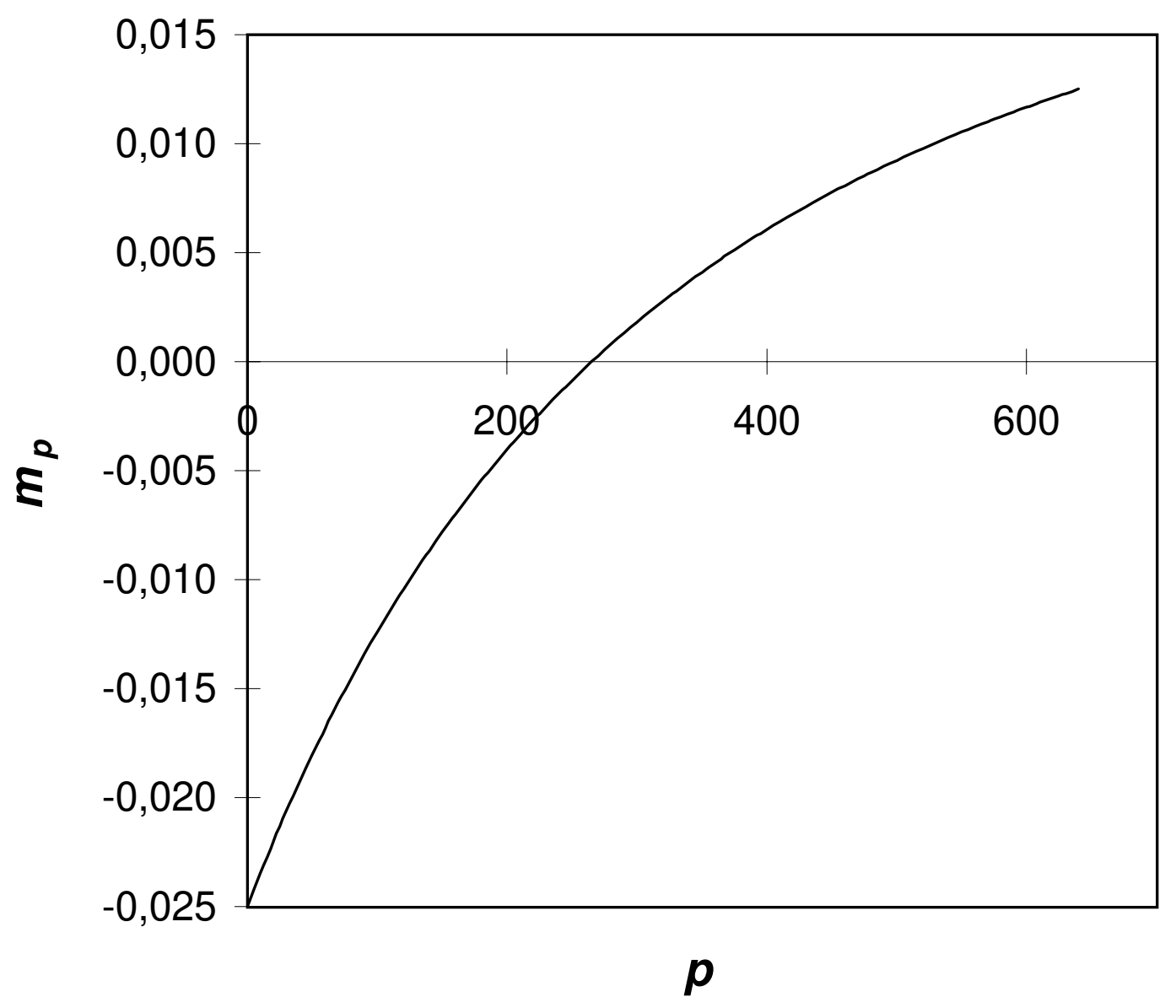

Figure 2 


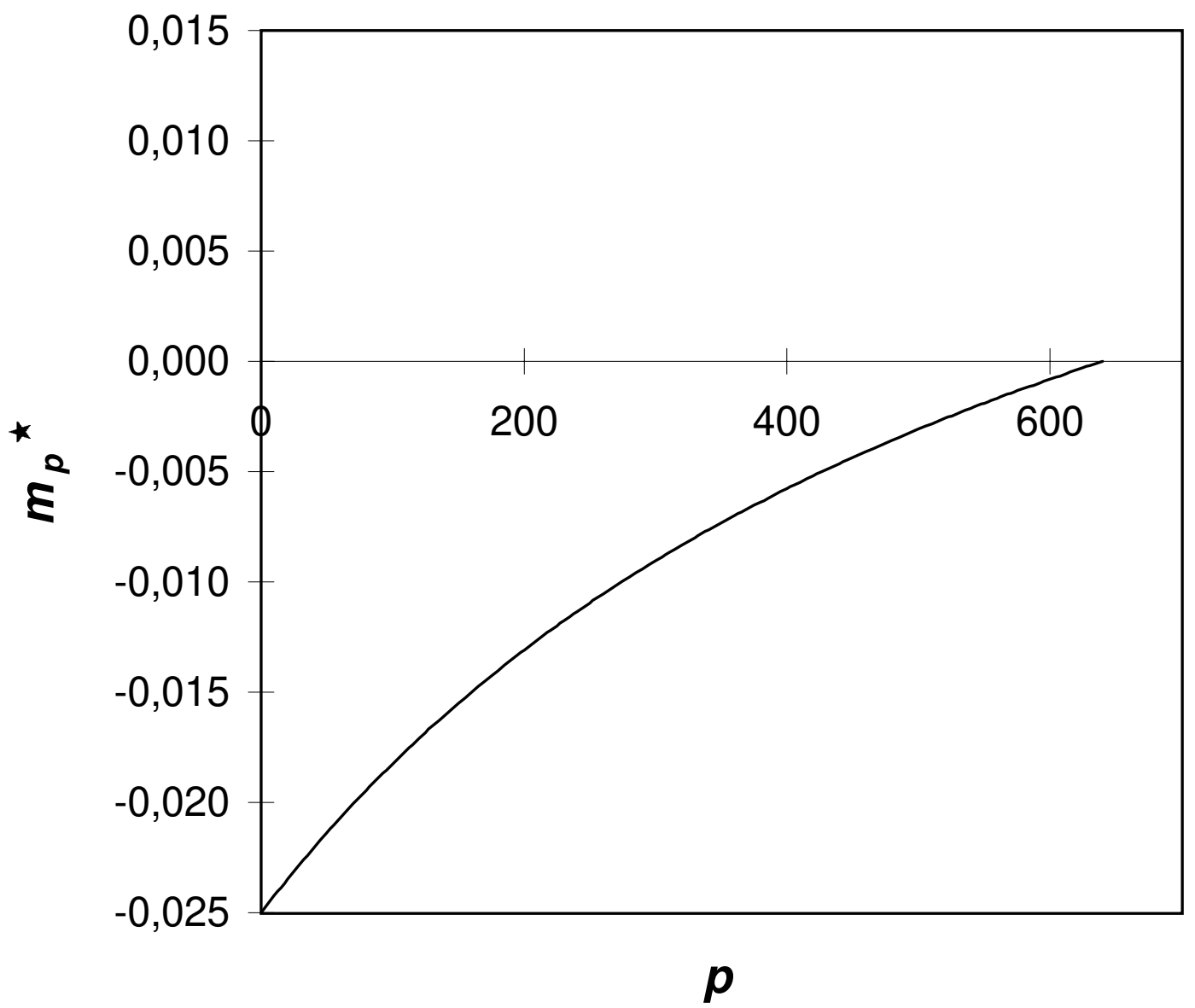

Figure 3 